\title{
QUALIDADE FÍSICAS E QUÍMICAS DE MORANGO PASSA EM DIFERENTES EMBALAGENS
}

\author{
Amanda Gonçalves Guimarães ${ }^{1}$, Celso Mattes de Oliveira ${ }^{2}$, Gilmar Vieira ${ }^{3}$, Nísia Andrade Villela Dessimoni Pinto ${ }^{4}$
}

\section{RESUMO}

O morango apresenta elevada perecibilidade e, consequentemente, reduzida vida pós-colheita. Assim, a desidratação apresenta-se como alternativa para reduzir as perdas pós-colheita. O objetivo deste trabalho foi avaliar o tipo de embalagem e o tempo de armazenamento nas características físicas e químicas do morango desidratado. Foram utilizados morangos da cultivar 'Oso-Grande', selecionados, sanitizados, cortados transversalmente e desidratados à temperatura de $60 \pm 5^{\circ} \mathrm{C}$, até obter o teor de umidade de $20 \pm 2 \%$ de base úmida. As embalagens avaliadas foram: sacos de polietileno transparente de espessura 0,087 micras e baixa densidade sob vácuo e sem vácuo, e plásticos de celofane. As análises físicas e químicas avaliadas foram: teores de umidade, acidez titulável, sólidos solúveis, pH, vitamina $\mathrm{C}$, açúcares totais e redutores. Os morangos desidratados foram armazenados durante 180 dias à temperatura média ambiente de $20 \pm 2{ }^{\circ} \mathrm{C}$ e, umidade relativa média do ar, em torno de $78 \pm 2 \%$. O delineamento experimental utilizado foi inteiramente ao acaso em esquema fatorial $3 \times 7 \times 3$, e o efeito do tempo de armazenamento dentro de cada embalagem foi estudado utilizando análise de regressão. As embalagens foram comparadas pelo teste Tukey a 5\% de significância. A desidratação do fruto do morangueiro mostrou-se uma alternativa para acrescentar um novo produto no mercado, havendo uma concentração dos sólidos solúveis e uma baixa umidade. A embalagem de polietileno a vácuo foi a que melhor conservou as características físicas e químicas do morango passa, constatado sua eficiência como barreira na absorção de umidade. O tempo de armazenamento de 180 dias para as características físicas e químicas foi eficiente somente para os frutos de morangueiro embalados a vácuo.

Palavras chave: Fragaria ananassa Duch, desidratação, embalagem.

\section{ABSTRACT}

\section{PHYSICAL AND CHEMICAL QUALITY OF DRIED STRAWBERRY IN DIFFERENT PACKAGES}

The strawberry has high perishability, and consequently reduced postharvest life. Thus, dehydration IS as an alternative to reduce post-harvest losses. The aim of this study was to evaluate the type of packaging and storage time on physical and chemical characteristics of dehydrated strawberry. We used strawberries of the cultivar 'Oso Grande', sorted, sanitized, cut transversely and dehydrated at a temperature of $60 \pm 5{ }^{\circ} \mathrm{C}$ until reaching a moisture content of $20 \pm 2 \%$ (wet basis). The packages evaluated were: transparent polyethylene bags measuring 0.087 microns thick and low density under vacuum without vacuum, and plastic cellophane. The physical and chemical analyses conducted were: moisture content, titratable acidity, soluble solids, $\mathrm{pH}$, vitamin $\mathrm{C}$, total and reducing sugars. The dehydrated strawberries were stored for 180 days at average room temperature $\left(20 \pm 2^{\circ} \mathrm{C}\right)$ with relative humidity of the air around $78 \pm 2 \%$. The experimental design was completely randomized in a $3 \times 7 \times 3$ factorial, and the effect of storage time within each package was studied using the regression analysis. Packages were compared by the Tukey test at $5 \%$ of significance. Dehydration of the strawberry fruit showed to be an alternative to adding a new product on the market, presented a concentration of soluble solids and low moisture. Polyethylene bags under vacuum best retained the physical and chemical characteristics of the dehydrated strawberry, indicating its effectiveness as a barrier to absorption of moisture. Only the vacuum packaging was able to efficiently preserve the physical and chemical characteristics of the strawberry fruits for a period of 180 days.

Keywords: Fragaria ananassa Duch, dehydration, package

Recebido para publicação em 18/06/2012. Aprovado em 23/05/2013.

1 - Eng'. Agrônoma, Mestranda - FCA- UFVJM- Diamantina-MG, Bolsista CAPES. E-mail: amandagguimaraes@yahoo.com.br

2 - Eng. Agrônomo, Doutorando em Fitotecnia - UFLA- Lavras-MG, Bolsista CAPES. E-mail: celsodoliveira@yahoo.com.br

3 - Eng. Agrícola, Doutor Prof. Adjunto -FCA-UFVJM- Diamantina-MG, CEP 39100-000. E-mail: vieira@ufvjm.edu.br

4 - Bióloga, Doutora Prof ${ }^{a}$.Adjunta -DNUT-UFVJM- Diamantina-MG, CEP 39100-000. E-mail: nisiavillela@yahoo.com.br 


\section{INTRODUÇÃO}

A cultura do morangueiro (Fragaria ananassa Duch.) é apreciada em muitos países, por apresentar características sensoriais atrativas e nutricionais bem definidas, sendo assim, muito valorizados na comercialização (GIMENEZ et al., 2008). A cultura se desempenha também pela intensa mão de obra, que na maioria das vezes é familiar, contribuindo para a geração de renda e melhoria da qualidade de vida (OLIVEIRA et al., 2008).

Em função do seu caráter social, atualmente o cultivo do morango vem se desenvolvendo rapidamente em regiões contendo pequenas propriedades, sem tradição agrícola. Dentre estas regiões, destaca-se no Alto Vale do Jequitinhonha, a região do município de Datas e circunvizinhas, devido às suas características edafoclimáticas favoráveis, que segundo Conti et al. (2002), já que são áreas de clima tropical e de altitude elevada.

Um dos grandes problemas dos frutos de morangueiro é a baixa conservação pós-colheita, principalmente se atingirem o estágio de maturação avançado, não atendendo às exigências de comercialização in natura, pois os mesmos perdem tanto em qualidade como em textura e aparência (MIRANDA et al., 2012). Isto é devido à alta perecibilidade do produto, que possui uma rápida desidratação pelos seus tecidos, em função da alta taxa respiratória (MIRAHMADI et al., 2011), o que pode acarretar perdas consideráveis, tanto nutritivas quanto econômicas, sendo sua comercialização um desafio (REIS et al., 2008).

Diante disso, a introdução de tecnologias ou práticas pós-colheita, que incluem a diminuição de perda, maior tempo de comercialização e maior valorização do produto, são fundamentais para maior agregação de valor (BOBBIO; BOBBIO, 2001). Neste sentido, a desidratação que, segundo Souza Neto et al. (2005), é uma técnica que consiste na eliminação de água por evaporação, com transferência de calor e massa, em que o sólido a ser seco é exposto a uma corrente de ar quente que flui continuamente e, assim, a umidade é removida, é uma grande alternativa. Dentre as técnicas de desidratação, podem ser citados os processos de desidratação por convecção natural, realizada geralmente em estufas com circulação forçada, em diferentes tipos de secadores, aplicados a uma grande variedade de frutas e vegetais (NICOLETI et al., 2001).

A demanda por produtos processados, sensorialmente similares aos alimentos in natura, tem imposto novos requerimentos às embalagens (RAMOS et al., 2008). Isso porque a qualidade desses produtos pode alterar com o tempo de armazenamento. Esses produtos apresentam maior vida de prateleira se embalados e protegidos, para evitar o contato com o oxigênio e ganho de umidade (ALVES, 2001).

Os produtos desidratados exigem embalagens com alta barreira, que possam assegurar excelente proteção contra umidade, luz e oxigênio, além de boa resistência mecânica. As mais comuns são papel de celofane transparente, polietileno ou polipropileno e embalagens a vácuo (KOPF, 2008).

$\mathrm{O}$ benefício advindo da obtenção de frutos desidratados, acondicionados e embalados apropriadamente, incrementará a renda da família do agricultor e permitirá, ainda, o aproveitamento de toda a produção, propiciando a comercialização dos produtos fora da safra, facilitando o estoque, fixação da mão de obra e geração de lucros. A tecnologia de desidratação é de baixo custo, acessível e poderá ser adotada pelos pequenos agricultores da região. No entanto, os estudos de desidratação em morangos são escassos, sendo necessária a realização de mais pesquisas com este intuito.

Desta forma, o objetivo neste trabalho foi de obter o morango desidratado (passa), avaliar o tipo de embalagem e o tempo de armazenamento nas suas características físicas e químicas.

\section{MATERIAL E MÉTODOS}

Cerca de $160 \mathrm{~kg}$ de morango 'Oso Grande' foram colhidos nos estágios a $75 \%$ de maturidade, nas propriedades pertencentes à Associação dos Produtores de Frutas do Alto Jequitinhonha FRUTIVALE, do município de Datas - MG, $18^{\circ}$ $26^{\prime} 44^{\prime \prime}$ de latitude, $43^{\circ} 39^{\prime} 21^{\prime \prime}$ de longitude e $1.231 \mathrm{~m}$ de altitude.

Os frutos foram conduzidos ao laboratório de Tecnologia Biomassa do Cerrado- LTBC, da Universidade Federal dos Vales do Jequitinhonha e Mucuri- UFVJM, Campus JK, Diamantina-MG, onde foram selecionados, retirados manualmente os pecíolos e as sépalas. Os frutos foram lavados em água corrente, sanitizados com solução de hipoclorito de sódio a 4-6\% P.A, por 5 minutos, depois novamente lavados em água corrente e deixados sob uma tela de aço inox para escoamento da água.

Os morangos foram cortados transversalmente 
ao meio, colocados em bandejas e submetidos à secagem em desidratador (Polidryer) a gás e com ventilação de ar forçada, conforme fluxograma na Figura 1. Durante o processo, utilizou-se a temperatura de $60 \pm 5^{\circ} \mathrm{C}$, até obter o teor de umidade de $20 \pm 2 \%$ de base úmida, sendo monitorada com termohigrografo digital Marca Data Logger modelo HT-500, afixado na entrada do desidratador.

Após a desidratação, os morangos passa foram acondicionados em embalagens de celofane, polietileno de espessura 0,087 micras e baixa densidade a vácuo e sem vácuo, contendo amostras de $100 \mathrm{~g}$ cada uma. A embaladora de vácuo foi a de modelo VM-12, de bancada, da Orved \& Brock. Em seguida, foram armazenados à temperatura ambiente $\left(20 \pm 2{ }^{\circ} \mathrm{C}\right)$ e umidade relativa de $78 \pm 2 \%$, monitorados diariamente por termohigrógrafo digital e avaliados, por até 180 dias.

Aolongo do armazenamento: 0,30,60,90, 120, 150 e 180 dias foram realizadas análises físicas e químicas nos morangos passa, descritas a seguir.A umidade foi determinada por secagem em estufa a $105^{\circ} \mathrm{C}$, até peso constante Aoac (2000). Os resultados foram expressos em \% base úmida. $\mathrm{O} \mathrm{pH}$ foi obtido com auxílio de um peagâmetro digital ( $\mathrm{PH} /$ ION METER 450). Após a calibragem do aparelho com o uso de solução tampão ( $\mathrm{pH} 4,0$ e 7,0), os eletrodos foram mergulhados na polpa de morango de cada repetição, de cada tratamento (IAL, 2008). Os sólidos solúveis foram determinados por leitura em refratômetro de bancada portátil (QUÍMIS ISSO-9002), escala 0-32 ${ }^{\circ}$ Brix e os resultados expressos em ${ }^{\circ}$ Brix (IAL, 2008). Para a calibração prévia do equipamento, foi depositada no prisma uma gota de água destilada, sendo a escala aferida em zero. A acidez titulável foi determinada por titulação da amostra com uma solução titulante de hidróxido de sódio $(\mathrm{NaOH})$ na concentração 0,1 mol $_{c} \mathrm{~L}^{-1}$, padronizada com biftalato de potássio (titulometria de neutralização). Utilizouse solução de fenolftaleína como indicadora da viragem. Os resultados obtidos foram expressos em $\mathrm{g}$ ácido cítrico/100 g de morango (IAL, 2008). O teor de açúcares redutores totais foi extraído pelo método de Somogyi, adaptada por Nelson (1994). A leitura foi realizada em espectrofotômetro e, os resultados obtidos foram expressos em $\mathrm{g}$ por $100 \mathrm{~g}$ de polpa. A vitamina $\mathrm{C}$ foi determinada por método colorimétrico, baseado na redução do 2,6- diclorofenolindofenolsódico (DFI), padronizado com ácido ascórbico (AOAC, 2000). Os resultados foram expressos em mg ácido ascórbico/100 g morango.

O delineamento experimental utilizado foi o inteiramente casualisado em esquema fatorial $3 \times 7 \times 3$, em 3 embalagens, 7 tempos de

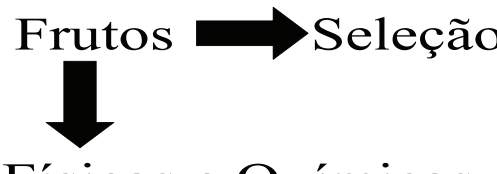

Análises Físicas e Químicas

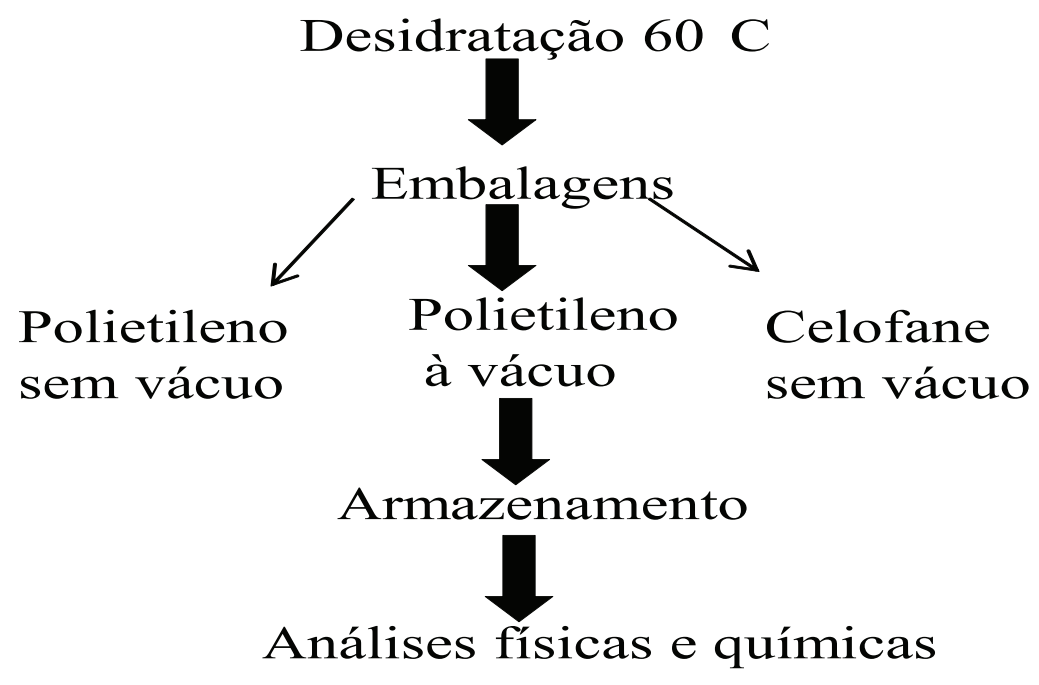

Figura 1. Fluxograma de obtenção e processamento do morango desidratado. 
armazenamento e 3 repetições. O efeito do tempo de armazenamento dentro de cada embalagem foi estudado utilizando análise de regressão. Para fazer a comparação entre as embalagens, foi aplicado o teste de Tukey ao nível de significância de 5\%. Os resultados obtidos foram analisados no programa SISVAR- Sistema para análise de variância para dados balanceados (FERREIRA, 2003).

\section{RESULTADOS E DISCUSSÃO}

No Quadro 1 mostram-se os parâmetros físicoquímicos dos morangos in natura e desidratados.

Observa-se que o teor médio da umidade nos morangos "in natura" foi de $89,07 \%$ e, quando desidratado, foi de 21,59\% de base úmida (Quadro 1). Fato de extrema importância na conservação das frutas desidratadas, no sentido de aumentar o tempo de armazenamento, inibindo o desenvolvimento de micro-organismos e preservando as características sensoriais e nutricionais do produto (OLIVEIRA et al., 2010).

No presente estudo, o teor de umidade dos morangos desidratados encontra-se dentro das faixas considerado ideal para frutas desidratadas, que é em torno de 20\% (RAMOS et al., 2008) e, de acordo com a Agência de Vigilância Sanitária (ANVISA), inferior a 25\% (BRASIL, 2010). Os dados obtidos neste trabalho corroboram com os dados obtidos por Oliveira et al. (2010), pesquisando a mesma cultivar de morangueiro (Oso Grande), observaram uma variação entre $20 \pm 22 \%$ de base úmida na desidratação dos frutos.

$\mathrm{O} \mathrm{pH}$ é o fator que exerce maior efeito seletivo no desenvolvimento da microflora (FRANCO; LANDGRAF, 2003). O pH do morango "in natura" foi de 3,42 , sendo este um indicativo para ser utilizado na industria, pois, segundo Passos (1982), morangos que apresentam o pH ácido, menor que 3,5, são apropriados para uso industrial. Em estudos com diferentes cultivares, Conti et al. (2002) e Oliveira et al. (2010), encontraram valores de $\mathrm{pH}$ para o morango "in natura" de 3,42 a 3,84, respectivamente, porém estudos realizados por Guimarães et al. (2013), observaram valor de $\mathrm{pH}$ no morango "in natura" para a cultivar Oso Grande de 3,23.

Quanto ao morango passa, observa-se que o $\mathrm{pH}$ teve um aumento de 3,42 para 3,81. Sabese, segundo Nutrição e Saúde (2011), que a proliferação de microorganismos durante $\mathrm{o}$ armazenagem é evidente em pHs superior a 4,5. Desta forma, no presente estudo, os morangos passa estão com valores inferiores àqueles favoráveis ao crescimento de micro-organismos e, assim, aptos a serem consumidos.

A acidez titulável indica a quantidade de ácidos orgânicos presentes na amostra (VILAS BOAS, 1999), importante para as características sensoriais, propriedades de geleificação da pectina e a síntese de pigmentos, além de atuar no controle do $\mathrm{pH}$ celular (CORDENUNSI et al., 2002). Os morangos passa apresentaram um pequeno aumento nos teores de acidez, quando comparados com os frutos "in natura", ou seja, de 0,74 para $0,84 \mathrm{~g} / 100 \mathrm{~g}$ de ácido cítrico. Este aumento de acidez titulável pode ser devido à redução de água resultante do processo de desidratação, que aumenta a concentração de

Quadro 1: Parâmetros físico e químicos dos morangos in natura e desidratados. Média \pm desvio padrão. Diamantina, UFVJM, 2009.

\begin{tabular}{lcc}
\hline \multicolumn{1}{c}{ Parâmetros } & In natura & Desidratado \\
\hline Teor de umidade (\% base úmida) & $89,07 \pm 0,76$ & $21,59 \pm 1,36$ \\
$\mathrm{pH}$ & $3,42 \pm 0,10$ & $3,81 \pm 0,01$ \\
Acidez total (\% ácido cítrico) (AT) & $0,74 \pm 0,10$ & $0,84 \pm 0,05$ \\
Sólidos Solúveis ( ${ }^{\circ}$ Brix) (SS) & $5,46 \pm 0,50$ & $85,07 \pm 5,08$ \\
SS/AT & $7,56 \pm 1,51$ & $101,16 \pm 1,99$ \\
Açúcares Totais (g/100g amostra) & $1,97 \pm 0,62$ & $6,88 \pm 0,35$ \\
Açúcares Redutores (g/100g amostra) & $1,50 \pm 0,43$ & \\
Vitamina C (mg ácido ascórbico /100g amostra) & $66,91 \pm 7,98$ & $2,94 \pm 0,31$ \\
\hline
\end{tabular}


açúcares, ácidos, sais e outros componentes que sejam suficientemente elevados para reduzir a quantidade de água e inibir, portanto, o desenvolvimento de micro-organismos (OLIVEIRA et al., 2010). Este aumento de acidez titulável é encontrado também nos trabalhos de Ramos et al. (2008), com desidratação em abacaxi. A acidez elevada pode depreciar a fruta, principalmente quando não está balanceada com um alto teor de sólidos solúveis (CHITARRA; CHITARRA, 2005).

O teor de sólidos solúveis indica a quantidade de açúcares existentes na fruta, considerando que outros compostos, em menores proporções tais como ácidos, vitaminas, aminoácidos e pectinas também podem estar presentes (KLUGE et al., 2002). O teor de sólidos solúveis nos morangos passa foi de $85,07^{\circ}$ Brix, apresentando-se quinze vezes maior ao dos morangos "in natura", que foi de 5,46 ${ }^{\circ}$ Brix. Esse aumento do morango fresco para o desidratado é devido à perda de água dos frutos e, consequentemente, à concentração de sólidos solúveis (CHITARRA; CHITARRA, 2005).

A relação entre os sólidos solúveis e a acidez titulável (SS/AT) demonstra o balanço entre açúcar e acidez, determinando o sabor dos frutos (THÉ et al., 2001). No presente trabalho, este valor foi de 7,56 no morango "in natura" e, no morango desidrato esta relação foi bastante alta $(101,16)$. Isto foi devido ao grande aumento de sólidos solúveis em relação à acidez titulável. Quando esta razão é muito baixa, o produto é insípido e perde qualidade (AKED, 2002).

Os principais açúcares em frutos são: glicose, frutose e sacarose e, quando solúveis, estes são responsáveis pela doçura, sabor e cor atrativas como derivado das antocianinas e pela textura, quando combinados com polissacarídeos estruturais (GOMES et al., 2002). Os valores de açúcares redutores totais no morango "in natura" foram $1,97 \mathrm{~g} / 100 \mathrm{~g}$, sendo próximos aos encontrados por Guimarães et al. (2013), de 1,91 g/100 g. Nos morangos passa os teores de açúcares redutores totais tiveram um leve aumento com 2,94g/100 g. Sabe-se que a eliminação de água no processo de secagem conduz ao incremento destes constituintes (PEREIRA et al., 2006).

Por fim, o papel da vitamina $C$ é fundamental no desenvolvimento e regeneração dos músculos, pele, dentes e ossos, na formação do colágeno e na regulação da temperatura corporal (ANDRADE et al., 2002). Os teores de vitamina $\mathrm{C}$ no morango "in natura" foi de $66 \mathrm{mg} / 100 \mathrm{~g}$. De acordo com os dados do Quadro de composição química dos alimentos (Usda, 2012), o teor de vitamina $\mathrm{C}$ de morangos in natura é, em média de $59,80 \mathrm{mg} / 100$ g. Com a desidratação houve redução destes teores valores para 35,69 mg/100 g. Esta redução é influenciada por diversos fatores como: oxigênio, $\mathrm{pH}$, luz, temperatura e conteúdo de umidade ou atividade da água (GABAS et al., 2003).

Os valores do teor de umidade e $\mathrm{pH}$ nos morangos passa, em diferentes embalagens, ao longo do tempo de armazenamento, podem ser observados nas Figuras 2 e 3.

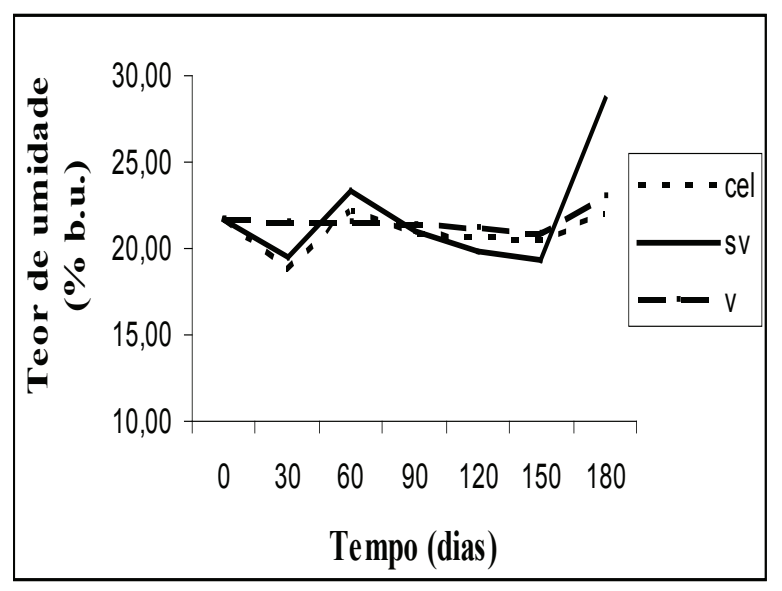

Figura 2. Teores de umidade dos morangos passa embalados em celofane (Cel), polietileno sem vácuo (SV) e polietileno à vácuo $(\mathrm{V})$ ao longo de 180 dias de armazenamento.

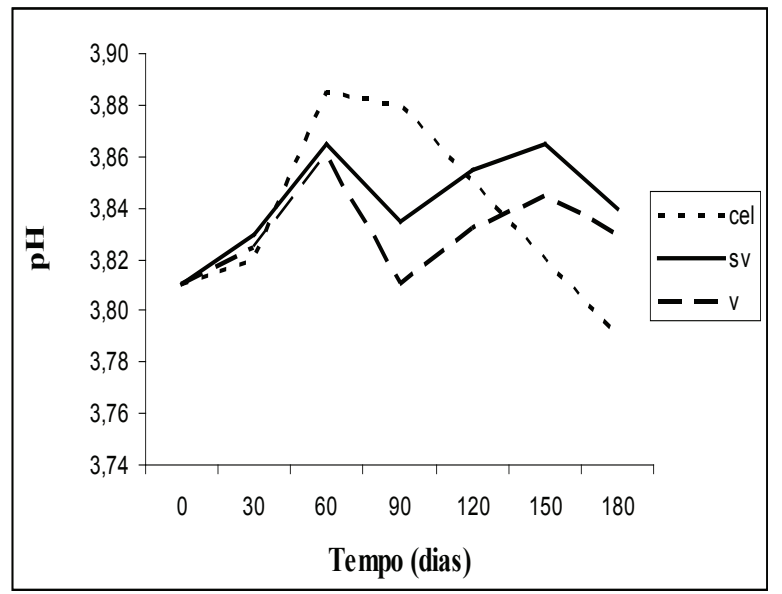

Figura 3. Valor do $\mathrm{pH}$ dos morangos passa embalados em celofane (Cel), polietileno sem vácuo (SV) e polietileno à vácuo $(\mathrm{V})$ ao longo de 180 dias de armazenamento 
Os teores de umidade nos morangos passa embalados com polietileno sem vácuo tiveram uma variação ao longo do tempo, com aumento acentuado, principalmente nos últimos 30 dias (Figura 2). Já as embalagens de celofane e em polietileno a vácuo, não variaram, ou variaram muito pouco quanto a estes teores. A eficiência da embalagem à vácuo é devido a pressão do fruto à embalagem, reduzindo assim as dimensões das células e de espaço livre na embalagem, absorvendo pouca umidade (ARAÚJO et al., 2009), sendo que a alta umidade pode propiciar o aparecimento de micro-organismos. As embalagens á vácuo e celofane mantiveram o teor de umidade mais baixo que a embalagem de polietileno sem vácuo durante o armazenamento. Ramos et al. (2008), não observaram variações nos teores de umidade em frutos de abacaxi desidratados, embalados em policloreto de vinilideno transparente.

Em relação aos teores de $\mathrm{pH}$ nos morangos passa (Figura 3), na embalagem com celofane houve pouca variação ao longo do tempo de armazenamento, comparada com as demais em que praticamente não alteram.

Nas Figuras 4 e 5, observam-se, respectivamente, os teores de sólidos solúveis e acidez titulável dos morangos passa, em diferentes embalagens, ao longo do tempo de armazenamento.

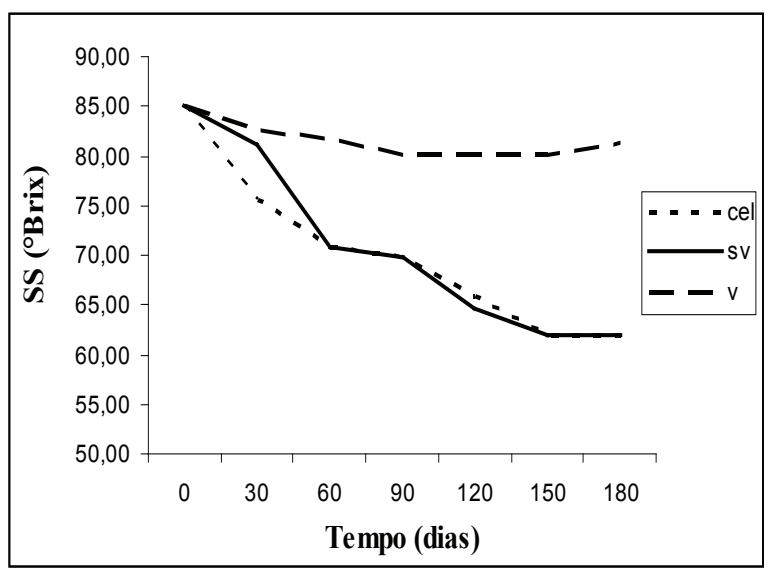

Figura 4. Sólidos solúveis dos morangos passa embalados em celofane (Cel), polietileno sem vácuo (SV) e polietileno à vácuo $(\mathrm{V})$ ao longo de 180 dias de armazenamento.

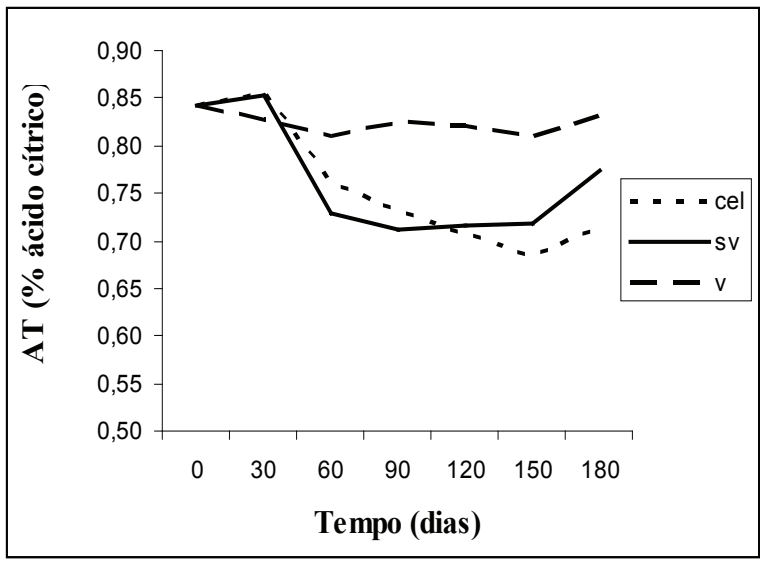

Figura 5. Acidez titulável dos morangos passa embalados em celofane (Cel), polietileno sem vácuo (SV) e polietileno à vácuo $(\mathrm{V})$ ao longo de 180 dias de armazenamento.

Houve uma intensa diminuição de sólidos solúveis no morango desidratado, embalado em polietileno sem vácuo e embalagem de celofane, durante os 180 dias de armazenamento (Figura 4), o que pode ser atribuído ao ganho dos teores de umidade. O mesmo foi observado nos trabalhos de Cano-Chauca (2002), com banana passa e também em Ramos et al. (2008), com abacaxi desidratado. Já na embalagem em sacos de polietileno a vácuo, não houve variação significativa no teor de sólidos solúveis durante o armazenamento. A diminuição no teor de sólidos solúveis deprecia o sabor do fruto, então a embalagem a vácuo manteve seus níveis, o que pode ser devido a um menor consumo de reservas ao longo do período de armazenamento.

Os teores de acidez titulável nas amostras de morangos desidratados, embalados em celofane e sacos de polietileno sem vácuo, tiveram uma diminuição brusca ao longo do tempo de armazenamento. Já na embalagem de polietileno a vácuo não se observou variação significativa durante o tempo de armazenamento (Figura 5), permanecendo valores próximos ao encontrado no morango in natura.

A relação sólidos solúveis (SS) com acidez titulável (AT), analisadas nas amostras dos morangos desidratados é mostrada na Figura 6 e 7, respectivamente. 


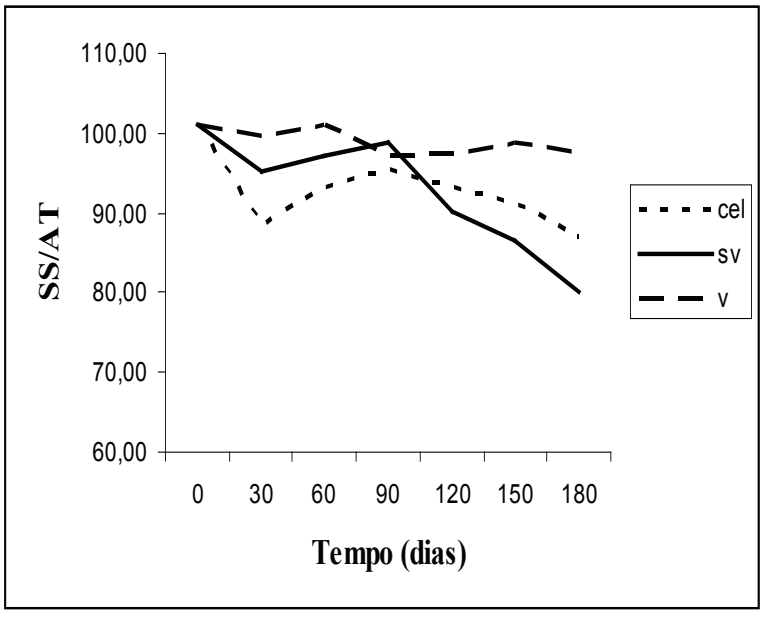

Figura 6. Relação SST/ATT dos morangos passa embalados em celofane (Cel), polietileno sem vácuo (SV) e polietileno à vácuo $(\mathrm{V})$ ao longo de 180 dias de armazenamento.

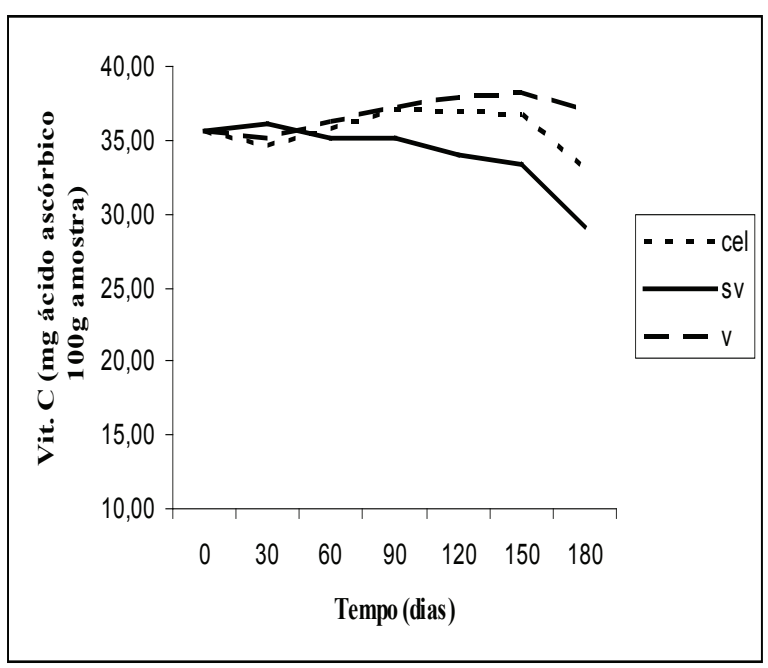

Figura 7. Vitamina $\mathrm{C}$ dos morangos passa embalados em celofane (Cel), polietileno sem vácuo (SV) e polietileno à vácuo $(\mathrm{V})$ ao longo de 180 dias de armazenamento.

Arelação sólidos solúveis(SS) comacidez titulável (AT) no morango desidratado reduziu independente da embalagem ao longo do tempo, entretanto, apenas nas embalagens de polietileno sem vácuo essa relação foi significativa. Quando esta razão é muito baixa, o produto é insípido e perde qualidade (AKED, 2002). $\mathrm{O}$ que demonstra que as embalagens de celofane e polietileno à vácuo mantiveram os índices durante $\mathrm{o}$ tempo de armazenamento.

Quanto aos teores de vitamina C (Figura 7), nos morangos passa embalados em sacos de polietileno sem vácuo, houve uma diminuição destes ao longo do armazenamento. Já nas outras embalagens esta redução não foi significativa. Estudos realizados por Pereira et al. (2006), com embalagens de polietileno sem vácuo em desidratação de tomates em pó, comprovaram que os teores de vitamina $\mathrm{C}$, durante os 60 dias de armazenamento, não apresentaram variação significativa.

Os teores de açúcares totais e redutores nos morangos passa, embalados em diferentes embalagens ao longo do tempo de armazenamento, podem ser observados nas Figuras 8 e 9 .

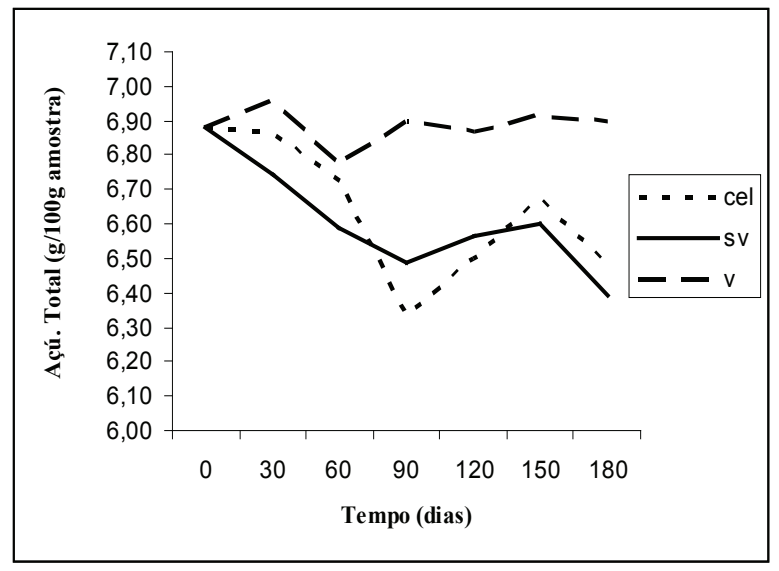

Figura 8. Açúcares totais dos morangos passa embalados em celofane (Cel), polietileno sem vácuo (SV) e polietileno à vácuo $(\mathrm{V})$ ao longo de 180 dias de armazenamento.

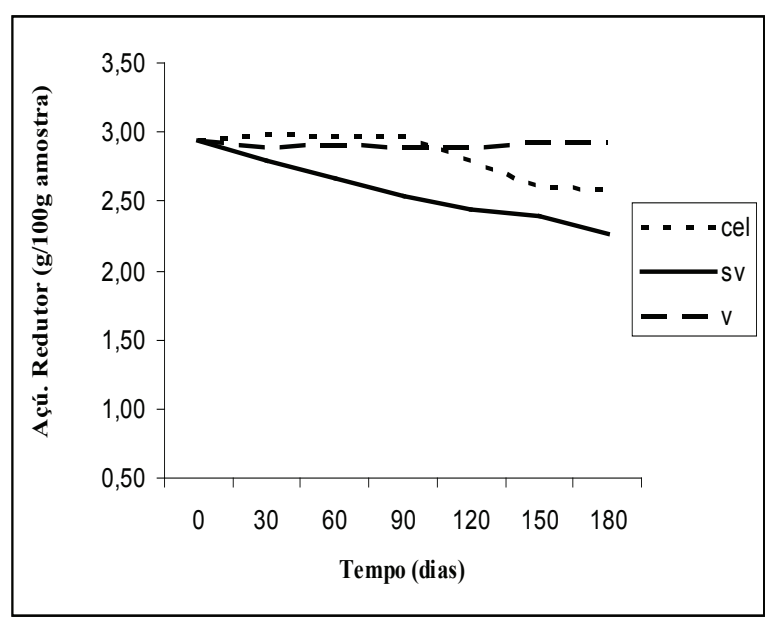

Figura 9. Açúcares redutores dos morangos passa embalados em celofane (Cel), polietileno sem vácuo (SV) e polietileno à vácuo $(\mathrm{V})$ ao longo de 180 dias de armazenamento.

\section{REVENG}

306-316p. ENGENHARIA NA AGRICULTURA, VIÇOSA - MG, V.22 N.4, JULHO / AGOSTO 2014 
Os teores de açúcares nos morangos embalados em papel celofane e polietileno sem vácuo não diferiram entre si, tendo uma diminuição brusca ao longo do período de armazenamento. Já na embalagem de polietileno a vácuo, houve pouca variação durante o tempo de armazenamento. Lima et al. (2007) informam que um elevado teor destes nos frutos, além de satisfazer a preferência do consumidor, é muito importante quando o produto é industrializado, pois reduz a necessidade de adição de açúcar.

O Quadro 2 mostra as equações de regressão dos parâmetros físicos e químicos do morango desidratado em função do tempo de armazenamento e tipo de embalagem utilizada.

No Quadro 3 mostram-se os valores médios dos atributos físico-químicos do morango desidratado e armazenado em diferentes tipos de embalagens.
A umidade apresentou diferenças significativas entre as embalagens. O teor de umidade aumentou nos morangos passa, embalados em polietileno sem vácuo. A embalagem de polietileno com vácuo conservou mais o teor de umidade, ao longo do tempo de armazenamento. Conti et al. (2008) encontraram teores de umidade entre 21,8 a 20,1\% de base úmida em abacaxi desidratado, utilizando embalagem de polietileno transparente e polivinilcloreto a vácuo, respectivamente, aproximando-se dos valores apresentados neste trabalho, com $21,91 \%$ e $20,94 \%$ de base úmida, embalados com polietileno a vácuo e sem vácuo, respectivamente.

A variação do $\mathrm{pH}$ do morango passa, nas três embalagens, manteve-se em teores desejáveis, pois segundo Silva et al. (1994), um pH inferior a 4,5 impede a proliferação de micro-organismo no produto final.

Quadro 2. Equações de regressão dos parâmetros físico-químicos do morango desidratado em função do tempo de armazenagem e embalagens utilizadas.

\begin{tabular}{|c|c|c|c|}
\hline \multirow{3}{*}{ Parâmetros } & \multicolumn{3}{|c|}{ Equações de regressão } \\
\hline & \multicolumn{3}{|c|}{ Embalagens } \\
\hline & Celofane sem vácuo & Polietileno s / vácuo & Polietileno c / vácuo \\
\hline Teor de umidade (\% base úmida) & $\begin{array}{c}y=20,99- \\
0,011 x+0,00 x^{2}\end{array}$ & $* \mathrm{y}=22,28-0,07 \mathrm{x}+0,00 \mathrm{x}^{2}$ & $y=21,85-0,20 x+0,00 x^{2}$ \\
\hline pH & $\begin{array}{c}* \mathrm{y}=3,80+0,00 \mathrm{x}-0,00 \mathrm{x}^{2} \\
\mathrm{R}^{2}=0,83\end{array}$ & $\begin{array}{c}\mathrm{y}=3,81+0,00 \mathrm{x}-0,00 \mathrm{x}^{2} \\
\mathrm{R}^{2}=0,65\end{array}$ & $\mathrm{y}=3,82+0,00 \mathrm{x}-0,00 \mathrm{x}^{2}$ \\
\hline SST ( ${ }^{\circ}$ Brix) & $\begin{array}{c}* y=83,78- \\
0,23 x+0,00 x^{2} R^{2}=0,97\end{array}$ & $\begin{array}{c}* \mathrm{y}=85,93-0,25 \mathrm{x}+0,00 \mathrm{x}^{2} \\
\mathrm{R}^{2}=0,97\end{array}$ & $\begin{array}{c}\mathrm{y}=85,02-0,08 \mathrm{x}+0,00 \mathrm{x}^{2} \\
\mathrm{R}^{2}=0,98\end{array}$ \\
\hline ATT (\% ácido cítrico) & $\begin{array}{c}* \mathrm{y}=0,87-0,00 \mathrm{x}+0,00 \mathrm{x}^{2} \\
\mathrm{R}^{2}=0,88\end{array}$ & $\begin{array}{c}* \mathrm{y}=0,87-0,02+0,00 \mathrm{x}^{2} \\
\mathrm{R}^{2}=0,81\end{array}$ & $y=0,84-0,00 x+0,00 x^{2}$ \\
\hline SST/ATT & $y=96,76-0,04 x$ & $\begin{array}{c}* \mathrm{y}=99,11+0,02 \mathrm{x}-0,00 \mathrm{x}^{2} \\
\mathrm{R}^{2}=0,90\end{array}$ & $y=101,16-0,04 x+0,00 x^{2}$ \\
\hline 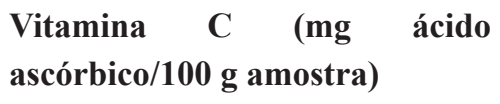 & $y=34,61+0,05 x-0,00 x^{2}$ & $\begin{array}{c}* \mathrm{y}=35,49+0,03 \mathrm{x}-0,00 \mathrm{x}^{2} \\
\mathrm{R}^{2}=0,93\end{array}$ & $\begin{array}{c}\mathrm{y}=35,07+0,31 \mathrm{x}-0,00 \mathrm{x}^{2} \\
\mathrm{R}^{2}=0,76\end{array}$ \\
\hline Açúcares Totais ( $\mathrm{g} / 100 \mathrm{~g}$ amostra & $* \mathrm{y}=6,94-0,01 \mathrm{x}+0,00 \mathrm{x}^{2}$ & $\begin{array}{c}* \mathrm{y}=6,86-0,00 \mathrm{x}+0,00 \mathrm{x}^{2} \\
\mathrm{R}^{2}=0,79\end{array}$ & $y=6,90-0,00 x+0,00 x^{2}$ \\
\hline $\begin{array}{l}\text { Açúcares Redutores }(\mathrm{g} / 100 \mathrm{~g} \\
\text { amostra) }\end{array}$ & $\begin{array}{c}y=2,96+0,00 x-0,00 x^{2} \\
R^{2}=0,91\end{array}$ & $\begin{array}{c}* y=2,94-0,00 x+0,00 x^{2} \\
R^{2}=0,99\end{array}$ & $y=2,93-0,00+0,00 x^{2}$ \\
\hline
\end{tabular}

*Significativo $\mathrm{p}<0,05$ 
Quadro 3. Valores médios dos atributos físico-químicos do morango desidratado armazenado em três tipos de embalagens*

\begin{tabular}{lcccccccc}
\hline & $\begin{array}{c}\text { Teor de } \\
\text { umidade } \\
\text { (\% b.u. })\end{array}$ & pH & $\begin{array}{c}\text { SS } \\
\left({ }^{\circ} \text { Brix }\right)\end{array}$ & $\begin{array}{c}\text { AT(\% } \\
\text { ácido } \\
\text { cítrico })\end{array}$ & $\begin{array}{c}\text { SS/ } \\
\text { AT }\end{array}$ & $\begin{array}{c}\text { Vit. C(mg ác. } \\
\text { ascórbico/100 } \\
\text { g amostra })\end{array}$ & $\begin{array}{c}\text { Açúcares } \\
\text { Totais(g/100 g } \\
\text { amostra }\end{array}$ & $\begin{array}{c}\text { Açúcares } \\
\text { Red. (g/100 } \\
\text { g amostra })\end{array}$ \\
\cline { 2 - 9 } Cel & $21,56 \mathrm{ab}$ & $3,84 \mathrm{a}$ & $70,17 \mathrm{~b}$ & $0,76 \mathrm{~b}$ & $92,80 \mathrm{~b}$ & $35,67 \mathrm{~b}$ & $6,64 \mathrm{~b}$ & $2,83 \mathrm{a}$ \\
PSV & $21,91 \mathrm{a}$ & $3,84 \mathrm{a}$ & $70,77 \mathrm{~b}$ & $0,76 \mathrm{~b}$ & $92,76 \mathrm{~b}$ & $34,09 \mathrm{c}$ & $6,61 \mathrm{~b}$ & $2,57 \mathrm{~b}$ \\
PV & $20,94 \mathrm{~b}$ & $3,83 \mathrm{~b}$ & $81,56 \mathrm{a}$ & $0,82 \mathrm{a}$ & $99,04 \mathrm{a}$ & $36,79 \mathrm{a}$ & $6,88 \mathrm{a}$ & $2,91 \mathrm{a}$ \\
\hline Média & 21,47 & 3,84 & 74,17 & 0,78 & 94,86 & 35,52 & 6,71 & 2,77 \\
\hline C.V. & 4,28 & 0,33 & 3,97 & 4,60 & 4,57 & 4,14 & 2,36 & 4,83 \\
\hline
\end{tabular}

*Médias seguidas com mesma letra, na coluna, são iguais entre si pelo teste de Tukey (5\%).; Cel- celofane sem vácuo; $\mathrm{SV}$ - polietileno sem vácuo; $\mathrm{V}$ - polietileno a vácuo.

Nos teores de sólidos solúveis, a embalagem com papel celofane e polietileno sem vácuo não mostrou diferença significativa entre si, durante o tempo de armazenamento, ao contrário do que se observou na embalagem de polietileno com vácuo.

Os valores médios de AT e SS/AT não diferiram nas embalagens de papel celofane e polietileno sem vácuo, porém, diferiram na embalagem de polietileno com vácuo durante o armazenamento.

Quanto aos teores de vitamina C, houve diferença significativa nas três embalagens. $\mathrm{Na}$ embalagem de polietileno com vácuo, este parâmetro não oscilou durante o armazenamento, $o$ que pode estar relacionado com o teor de umidade. Já nas embalagens de papel celofane e polietileno sem vácuo, houve maior degradação da vitamina $\mathrm{C}$, sendo o contato com o ar e o aumento da umidade os principais fatores responsáveis pela alteração (GABAS et al., 2003).

Em relação aos teores de açúcares totais nas embalagens de papel celofane e polietileno sem vácuo, não se percebeu diferença, porém, estas diferiram na embalagem de polietileno com vácuo durante o armazenamento. Já os teores de açúcares redutores nas embalagens de papel celofane e polietileno com vácuo não apresentaram diferença entre si.

\section{CONCLUSÃO}

- A desidratação do fruto do morangueiro mostrou-se uma alternativa para acrescentar um novo produto no mercado, havendo uma concentração dos sólidos solúveis e uma baixa umidade;

- A embalagem de polietileno a vácuo foi a que melhor conservou as características físicas e químicas do morango passa, constatado sua eficiência como barreira na absorção de umidade;

- O tempo de armazenamento de 180 dias para as características físicas e químicas foi eficiente somente para os frutos de morangueiro embalados a vácuo.

\section{AGRADECIMENTOS}

A FAPEMIG, pelo suporte financeiro concedido para a realização desta pesquisa, e a FRUTIVALE, pelo apoio por ter cedido os frutos de morangos.

\section{REFERÊNCIAS BIBLIOGRÁFICAS}

AKED, J. "Maintaining the postharvest quality of fresh fruits and vegetables". In: JONGEN, W. (ed). Fruit and vegetable processing: Improving quality. CRC Press, Boca Raton. 2002, p.388.

ANDRADE, R.S.G. de; DINIZ, M.C.T.; NEVES, E.A.; NÓBREGA, J.A. Determinação e distribuição de ácido ascórbico em três frutos tropicais. Eclética Química, São Paulo, v.27, n. especial, 2002.

\section{REVENG 306-316p.}


AOAC - Association of Official Analytical Chemists. Ofiicial Methods of Analysis of Association of Official Analytical Chemists. 17 ed. Arlington, 2000.

ALVES, R.M.V. Embalagem para frutas e hortaliças desidratadas e frutas secas. Campinas: CEITEA/ITAL, 2001, 12p.

ARAÚJO, N.M.; GUSMÃO, M.T.A.; ROCHA, M.M.B.; SERRÃO, B.O. Armazenamento a vácuo de manga 'tommy atkins' minimamente processada. Rev. Ciênc. Agrár., Belém, n.51, p.9-24, 2009.

BOBBIO, P.A.; BOBBIO, F.O. Química do processamento de alimentos. 3 . ed. São Paulo: Varela, 2001,143p.

BRASIL. Resolução CNNPA n.12, de 1978. Normas Técnicas Especiais. Diário Oficial da União, Brasília, 23 de julho de 1978. Disponível em: <http: //e legis.anvisa.gov.br/leisref/public/ showAct.php?id=16216\&word $>$. Acesso em 08 Junho de 2010.

CANO-CHAUCA, M. Análisis físico-químico, sensotial y microbiológico de banana passa. Servicio de información y documentación alimentaria. Alimentaria , Madrid, v.329, p.119122, Enero-Febr, 2002.

CHITARRA, M.I.F.; CHITARRA, A.B. Pós-colheita de frutas e hortaliças: Fisiologia e Manuseio. 2 ed. ver. E ampl. Lavras: UFLA, 2005, 785p.

CONTI, J.H.; MINAMI, K.; TAVARES, F.C.A. Produção e qualidade de frutos de morango em ensaios conduzidos em Atibaia e Piracicaba. Horticultura Brasileira, v.20, n.1, p.10-17, 2002.

CORDENUNSI, B.R.; NASCIMENTO, J.R.O.; GENOVESE, M.I.; LAJOLO, F.M. Influence of cultivar on quality parameters and chemical composition of strawberry fruits grown in Brazil. Journal of Agricultural and Food Chemistry, Los Angeles, v.50, n.9, p.2581-2586, 2002.

FERREIRA， D.F.; SISVAR: um programa para análises e ensino de estatística. Revista Symposium, Lavras, v. 6, p.36-41, 2008.

FRANCO, B.D.G.M.; LANDGRAF, M. Microbiologia de Alimentos. São Paulo. Atheneu, 2003,182 p.

GABAS,A.L.;TELIS-ROMERO,J.;MENEGALLI, F.C. Cinética de degradação do ácido ascórbico em ameixas liofilizadas. Ciência e Tecnologia de Alimentos, Campinas, v.23, p.1-11, 2003.

GIMENEZ, G.; ANDRIOLO, J.; GODOI, R. Cultivo sem solo do morangueiro. Ciência Rural, Santa Maria, v. 38, p.273-279, 2008.

GOMES, P.M.A.; FIGUEIREDO, R.M.F.; QUEIROZ, A.J.M. Caracterização e isotermas de adsorção de umidade da polpa de acerola em pó. Revista Brasileira de produtos agroindustriais, Campina Grande, v.4, n.2, p.157-165, 2002.

GUIMARAES, A.G.; VIEIRA, G; BATISTA A. G.; PINTO, N.A.V.D.; VIANA, D.J.S. Características físico-químicas e antioxidantes de cultivares de morangueiro no Vale do Jequitinhonha. Tecnol. \& Ciên. Agropec., João Pessoa, v.7, n.2, p.35-40, 2013.

KLUGE, R.A. et al. Fisiologia e manejo póscolheita de frutas de clima temperado. 2 ed. Campinas Livraria e Editora Rural, 2002, 214p.

KOPF, C. Técnicas do processamento de frutas para a agricultura familiar. Boletim Técnico. Guarapuava: Unicentro, 2008, 62p.

IAL - Instituto Adolfo Lutz. Métodos FísicoQuímicos para Análise de Alimentos. $4^{\mathrm{a}} \mathrm{ed}$., $1^{\mathrm{a}} \mathrm{Ed}$. Digital, São Paulo: 2008.

LIMA, L.C.; DIAS, M.S.C.; CASTRO, M.V.de.; RIBEIRO JÚNIOR, P.M.;. SILVA. E.B. Controle da antracnose e qualidade de mangas (Mangifera indica, L.) cv. Haden, após tratamento hidrotérmico e armazenamento refrigerado em atmosfera modificada. Ciência Agrotecnologia, Lavras, v.31, n.2, p.298-304, 2007. 
MIRAHMADI, F.; HANAFI, Q. M.; ALIZADEH, M.; MOHAMADI, H.; SARSAIFEE, M. Effect of low temperature on physico-chemical properties of different strawberry cultivars. African Journal of Food Science and Technology. v.2, n.5, p.109115, 2011.

MIRANDA, T,G. ; Lfetá ; PINTO, N.A.V.D.; VIEIRA, G. Avaliação do morango em calda submetido a diferentes concentrações de açúcar e condições de armazenamento. Alimentos e Nutrição, v.23, p.307-315, 2012.

NELSON, N.A.A photometric adaptation of Somogy method for the determination of glucose. The Journal of Biological Chemistry, Baltimore, v.135, n.1, p.136-175, 1994.

NICOLETI, J.F; TELIS-ROMERO, R.; TELIS, V.R.N. Air-drying of fresh and osmotically pretreated pinapple slices: fixed air temperature versus fixed slices temperature drying kinetcs. Drying Technology, v.19, n.9, p.2175-2191, 2001.

NUTRIÇÃO E SAÚDE. Apostila de Tecnologia de Alimentos Princípios. Disponível em $<$ http://www. ebah.com.br/tecnologia-dos-alimentos-pdf-a46754. html $>$. Acesso em 26 de janeiro de 2011.

OLIVEIRA, M.C.; GONÇALVES, A.; VIEIRA, G.; DESSIMONI, N.A.V.; Avaliação físicoquímica e perda de umidade do morango in natura desidratado em diferentes temperaturas, submetidos ou não a pausteurização. Revista Brasileira de Armazenamento, Viçosa, MG, v.35, n.2 p.107-114, 2010.

OLIVEIRA, R.P.; SCIVITTARO, W.B.; FINKENAUER D. Produção de morangueiro da cv. camino real em sistema de túnel. Revista Brasileira de Fruticultura, SP, v.30, n.3, p.681-684, 2008.

PASSOS, F.A. Caracterização de clones nacionais e introduzidos de morangueiro (Fragaria $X$ ananassa Duch.) visando o uso imediato na horticultura e o melhoramento genético. 1982. 116f. Tese (mestrado Genética e Melhoramento de Plantas). ESALQ, Piracicaba, 1982.
PEREIRA,I.E.;QUEIROZ,A.J.M.;FIGUEIREDO, R.M.F de. Características físicas e químicas do tomate em pó durante o armazenamento. Revista de Biologia e Ciência da Terra, v.6, n.1, 2006.

RAMOS, A.M.; QUINTERO,A.C.F.; FARRAONI, A.S.; SOARES, N.F.F.; PEREIRA, J.A.M. Effect of packing typo and storage time on the physicalchemical and microbiological quality of dehydrated pineapple. Alim. Nutr., Araraquara, v.19, n.3, p.159-169, jul./ set., 2008.

REIS, K.C.; SIQUEIRA, H.H.; ALVES, A.P.; SILVA, D.J.; LIMA, L.C.O. Efeito de diferentes sanificantes sobre qualidade de morango cv. Oso Grande. Ciênc. Agrotec., Lavras, v.32, n.1.1962002, 2008.

SILVA, J.B.C.; GIORDANO, L.B.; BOITEUX, L.S.; LOPES, C.A.; FRANÇA, F.H.; SANTOS, J.R.; FURUMOTO, O.; FONTES, R.R.; MAROUELLE, W.A.; NASCIMENTO, W.M.; SILVA, W.L.C.; PEDREIRA, W. Cultivo do Tomate (Lycopersicon esculentum Mill) para a industrialização. Instruções Técnicas do CNPH, n.12, p.6-7, 1994.

SOUZA NETO, M.A.; MAIA, G.A.; LIMA, J.R.; FIGUEIREDO, R.W.; SOUZA FILHO, M.S.M; LIMA, A.S. Desidratação osmótica de manga seguida de secagem convencional: avaliação das variáveis de processo. Ciênc. Agrotec., Lavras, v.29, n.5, p.1021-1028, 2005.

THÉ, P.M.P.; CARVALHO, V.D.; ABREU, C.M.F.; NUNES, R.F.; PINTO, N.A.V.D. Efeito da temperatura de armazenamento e do estádio de maturação sobre a composição química de abacaxi cv.Smooth cayene L. Ciênc. Agrotec., Lavras, v.25, n.2, p.356-363, 2001.

USDA - United States Department of Agriculture. Tabela de composição química de alimentos. Disponível em: $<$ http://www.unifesp.br/dis/ servicos/nutri/nutri.php?id=2245>. Acesso em: 10 de janeiro de 2011.

VILAS BOAS, E.V.B. Técnicas para diversas análises de alimentos. Lavras: UFLA/FAEPE/ DCA, 1999.74p. 